\title{
The Use of Real Options Methodology to Pasturelands Evaluation
}

\author{
${ }^{1}$ A. Michailidis, ${ }^{1}$ F. Chatzitheodoridis, ${ }^{2} \mathrm{I}$. Mountousis and ${ }^{2} \mathrm{~K}$. Papanikolaou \\ ${ }^{1}$ Department of Marketing and Quality Control of Agricultural Products, Technological Education \\ Institution of West Macedonia, Terma Kontopoulou str., 53100 Florina, Greece \\ ${ }^{2}$ Department of Animal Production, Faculty of Agriculture, Aristotle University of Thessaloniki \\ 54124 Thessaloniki, Greece
}

\begin{abstract}
This study demonstrates the utility of the real options approach to pasturelands investment analysis. The main objectives are to discuss the real options theory and show how it can be adopted to model uncertainty and managerial flexibility in pasture management (enlargement plan) and investment. Secondly, we show how to calculate the option values of selected options that may be available to managers of pasturelands. The study provides an empirical application, which compares a pasture investment using the static Net Present Value model and real options approach. The results show that according to the Net Present Value criterion, the enlargement plan of the pastureland is economically feasible. However, assuming the presence of uncertainty, application of a real options approach demonstrates that the Net Present Value may lead stakeholders to faulty decisions, as the investment plan is rejected.
\end{abstract}

Key words: Monte carlo simulation, pastureland, public investments, net present value, real options

\section{INTRODUCTION}

Traditional stockfarmings of ruminants (sheep, goat and cattle) utilize in a high degree the Greek native grazing lands. Both, herbaceous and woody plants should occur in grazing lands as they are considered important contributors to grazing animals nutrition ${ }^{[1-4]}$. Predominance of free grazing rural animals in the semimountainous and mountainous areas of Greece leads to overgrazing and consequently to degradation. Overgrazing coupled with wild fires leads to accelerate erosion creating marginal conditions towards desertification. However, because of the thoughtless use of pasturelands, often supplementary feed is required to compensate animals for pasture deficiencies ${ }^{[5]}$. The need of differentiation of use of these rangelands becomes continuously more intense since it requires solutions that will restore the biodiversity, will elevate the aesthetic value of the landscapes while in the meantime will maintain the traditional pastoralism.

Grassland nutritional quality is affected by abiotic and biotic environmental factors including soil type, climatic regime, botanical composition and range improvement practices ${ }^{[6-8]}$. On open rangelands, the quality and quantity of forage varies appreciably with climate and often leads to nutritional inadequacy ${ }^{[9]}$.

Financial analysis of pasture investments is a very complex task due to the required long planning horizon. The classical approach to analyze investment decisions is the use of traditional discounted cash flow (DCF) techniques such as the net present values (NPV), benefit/cost ratio $(\mathrm{B} / \mathrm{C})$ and internal rate of return (IRR). One of the notable problems with these approaches is the inability to account for managerial flexibility ${ }^{[10]}$. Another problem with the currently employed investment analysis is that the DCF is linear and static in nature and assumes that either the investment opportunity is reversible or if irreversible it is a now-or-never opportunity ${ }^{[11]}$. The traditional DCF techniques are based on the assumption that future cash flows follow a constant pattern that can be accurately predicted. Consequently, the DCF techniques fail to adequately address business assessment of growth opportunities or strategic alternatives arising from investments in large-scale commercial projects.

The field of pasture investments entails significant amounts of uncertainties, which make strategic managerial decision-making paramount. Due to the irretrievable nature of most pasture investments, greater focus must be placed upon investment evaluation. Thus, evaluating the adoption of any investment plan has to be accompanied by an investigation of the effect of uncertainty and risk. Real options theory is explicitly based on the idea that most investment projects embed a series of alternative actions. It follows that 'the ability to delay an irreversible investment can profoundly affect the decision to invest ${ }^{[11]}$.

Description of the study area: The study was conducted in the pasturelands of Municipality of Siatista, north-western Greece $\left(40^{\circ} 46^{\prime}\right.$ to $40^{\circ} 53^{\prime} \mathrm{N}$, $21^{\circ} 07^{\prime}$ ro $21^{\circ} 24^{\prime} \mathrm{E}, 500-1600 \mathrm{~m}$ above sea level). Most 
of the part of this area is mountainous $(>800 \mathrm{~m})$. The basic geological substrate of the whole research area is consisted of metamorphic rock textures (i.e. phyllites, gneisses and limestone) of the west Pelagonic geotectonic zone. The fertility of the soil varies depending on slope, exposure and vegetation. The mountain and topographic lie is quite tense and in combination to the climate conditions that change from zone to zone, create an impressive variation of flora from the lowest to the upper most zone. The climate approaches the Greek climatic conditions having as major characteristics long lasting and very hot summertime, soft winter and humidity in all seasons of year. The monthly average air temperature as well as rain precipitation in the decade $1992-2001$ was $13.0^{\circ} \mathrm{C}$ and $33.7 \mathrm{~cm}$ respectively ${ }^{[12]}$.

The pasturelands of study area were graded as seasonal ${ }^{[13]}$. That is, from $600-1400 \mathrm{~m}$, they are grazed during spring and autumn, while over $1400 \mathrm{~m}$ they are grazed in summer. Their productivity and readiness were mainly affected by climatic conditions. Climatic conditions are always related with the altitue of pasturelans.

The studied pasturelands cover 4,021 Ha area and they were grazed by 19,787 sheep and goats and 491 dairy cattle. Their productivity was about 4,107,207 kgr of DM. Grazing capacity was 91,271 , which means that these pasturelands could meet the nutrient requirements only for 13,039 animal units month (AUM) but not the existing 22,880 AUM in the study area. Stocking density was about $0.025 \mathrm{Ha} / \mathrm{AUM}$. Obviously stocking density was much higher than grazing capacity.

The pasturelands of Municipality of Siatista constitute appreciable natural resource for the region because they cover the most of the total extent of Municipality. Their total extent amounts in 4,027 Ha roughly. From these about $401 \mathrm{Ha}$ are forests in Mt. Bourinos, $313 \mathrm{Ha}$ are shrublands covered especially by oak (Quercus coccifera) (Ostrya carpinifolia) and (Carpinus orientalis), while 3,313 Ha are mountainous pasturelands.

Above ground biomass production was $1,020 \mathrm{Kg}$ $\mathrm{DM} / \mathrm{Ha}$. However, pasturelands were covered between 16 and $53 \%$ by weeds. From the numbers above it seems that, the fighting of weeds could give more $50 \%$ to $100 \%$ aboveground biomass production as well as better quality of grazable material, because the weeds are usually not eaten by ruminants.

In shrublands, biomass production varied from 590 to $690 \mathrm{Kg} \mathrm{DM} / \mathrm{Ha}$, which indicated low production because of the reduction of shrublands. This reduction is the effect sometimes of over-grazing and sometimes of under-grazing by ruminants.

Empirical model: The NPV criterion is used extensively in evaluating investment opportunities and is based on discounted cash flow methodology ${ }^{[14-16]}$. The typical cost-benefit model in infrastructure analysis can be represented as a choice between production "with" or "without" a specific investment. The choice between adopting and constructing a new infrastructure project or not can be based on comparison of the incremental investment costs of the new infrastructure project $I$ and the present value of its incremental net revenue flow, $V$ under certainty:

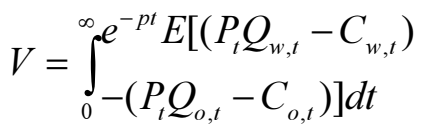

where, $p$ is the real discount rate; $t$ is the time period; $E$ is the expectations operator; $P$ is the output price; $Q$ is the output quantity; $C$ is the variable costs of production; and subscripts $w$ and $o$ indicate production "with" and "without" the investment respectively. The acceptance rule adopts projects where incremental net revenues are greater or equal to incremental investment costs $(V \geq I)$.

Recent developments in investment analysis point out that NPV formulas have shown to be limited when the conditions of irreversibility and uncertainty are present. More specifically, the NPV rule assumes a fixed scenario in which an investor starts and completes a project and garners a cash flow during some expected lifetime without permitting the investor to react in an uncertain and irreversible environment. Contingent claims analysis offers a range of possibilities to examine: investing today, or waiting and perhaps investing later or when the conditions are more favourable ${ }^{[11]}$. It allows uncertainty to influence the adoption decision directly and incorporates an extra value into the cost-benefit structure. Therefore, the simple NPV rule requires modification. The present value of the expected stream of cash from a project not only must be positive but also must exceed the cost of the project by an amount at least equal to the value of keeping alive the investment option ${ }^{[11]}$. Taking option values into account, one would invest in a project only if $V_{t}$ meets or exceeds $I$ plus the value of the option to invest in the future, $F(V)$. Under certainty, the value of the option to invest in the future is equal to zero, so the decision would not be reversed if it is profitable. Under uncertainty, the value of the option to invest in the future can be raised so the optimal time to invest would change.

Dixit and Pindyck ${ }^{[17]}$ suggest an optimal investment trigger using contingent claims analysis that offers a richer framework to evaluate such projects. Capital investments or irreversible investment opportunities are like financial call options. Therefore, a company with an investment opportunity has the option to spend money now or in the future (the exercise price) in return for an asset of some value (the project). The value of the opportunity to invest is described by the two equations, the value of waiting $\left(B R^{\beta}\right)$ and the value of investing $(R / \rho-K)^{[18]}$. 


$$
V(R)=\left\{\begin{array}{lll}
B R^{\beta} & \text { if } \quad \mathrm{R} \leq \mathrm{H} \\
R / \rho-K & \text { if } \quad \mathrm{R} \geq \mathrm{H}
\end{array}\right.
$$

where, $R$ are the expected uncertain returns from the investment; $B$ is a parameter equal to $(H-\rho K) / H^{\beta[19]} ; K$ is the sunk cost of initiating the investment project; $\rho$ is the opportunity cost of capital or risk-adjusted discount rate.

As discussed in Dixit ${ }^{[18]}$ investments with uncertainty and irreversibility have to be evaluated using a modified rate $\rho$ ' which include the effects of uncertainty and irreversibility. This modified minimum rate of return $\left(\rho^{\prime}\right)$ is used for the determination of the best investment behaviour. The relationship between discount rate of return $(\rho)$ and modified rate of return $(\rho ')$ can be understood by examining Equation 3, which describes how optimal rate of return changes as the multiplier $\beta / \beta-1$ increases the value of discount rate $(\rho)$.

$$
\rho^{\prime}=\frac{\beta}{\beta-1} \rho
$$

Pindyck $^{[19]}$ shows that $F(V)$ satisfies the following differential equation:

$$
\frac{1}{2} \mathrm{o}^{2} \mathrm{~V}^{2} \mathrm{~F}^{\prime \prime}(\mathrm{V})+(\mathrm{r}-\ddot{\mathrm{a}}) \mathrm{VF}^{\prime}(\mathrm{V})+\mathrm{rF}=0
$$

where, subscripts denote partial derivatives, $r$ denotes the risk-free interest rate and $\delta$ denotes the opportunity cost of delaying the actual investment. Together with the boundary conditions that, $\mathrm{F}(0)=0, \quad \mathrm{~F}\left(\mathrm{~V}^{*}\right)=\mathrm{V}^{*}-\mathrm{I}$ (value-matching condition) and $\mathrm{F}\left(\mathrm{V}^{*}\right)=1$ (smoothpasting condition), equation 4 possesses a unique solution:

$$
\begin{aligned}
& F(V)=A V^{\hat{a}_{1}} \\
& V^{*}=\frac{\hat{a}_{1}}{\hat{a}_{1}-1} E^{\prime}
\end{aligned}
$$

where,

$$
\hat{a}_{1}=\frac{1}{2}-(r-\ddot{a}) / o^{2}+\sqrt{\left[(r-\ddot{a}) / \dot{o}^{2}-\frac{1}{2}\right]^{2}+\frac{2 r}{o^{2}}}
$$

Both $\mathrm{F}(\mathrm{V})$ and $\mathrm{V}^{*}$ increase, if $\sigma$ increases. In other words, uncertainty increases the value of an investment opportunities, but decreases the amount of actual investing, since the threshold value, $\mathrm{V}^{*}$, rises.

The optimal timing of an investment, as a tangency between the value of investing $\left(i_{1} i_{2}\right)$ and the value of waiting $\left(w_{1} w_{2}\right)$ to invest, is described in Dixit ${ }^{[18]}$. The optimal investment trigger is at $H$, where the expected returns from initiating the investment are sufficiently high to make it optimal to proceed. To derive the optimal investment rule using dynamic programming, the value-matching condition and the smooth-pasting condition are satisfied simultaneously ${ }^{[18]}$ and the two equations are tangential (Fig. 1). The value-matching condition indicates that the marginal value of waiting is equal to the marginal value of investing. The solution of the smooth-pasting condition requires a unique point where both the boundary conditions are satisfied. In that point the investment must be implemented and decision makers must stop keep the option of investing on hold.

$$
H=\frac{\beta}{\beta-1} \rho \mathrm{K}
$$

where, $\rho K$ is the Marshallian trigger and

$$
\beta=1 / 2\left[1+\sqrt{1+\frac{8 \rho}{\sigma^{2}}}\right]>1
$$

The value of $\beta$ is a function of two known or estimate parameters $\left(\rho\right.$ and $\sigma^{2}$ ). As uncertainty about returns from investing increases, $\beta$ gets smaller and the defference between the Marshllian trigger $(M)$ and the optimal trigger increases. Raising the discount rate increases $\beta$ and reduces the difference between the Marshallian trigger $(M)$ and the optimal investment trigger $(H)$.

A Monte Carlo simulation model is used to estimate the variance on the value of investing in new technology or in a different project. The value of the opportunity to invest $(\mathrm{V})$ follows a process of geometric Brownian motion (GBM), given by Equation $10^{[20-22]}$.

$$
\frac{d V}{V}=\mu d t+\sigma d z
$$

where, $\mu$ is the constant drift rate, $\sigma$ is the constant variance rate and $d z$ is the increment of Wiener process, $z(t)$. The relationship between $d z$ and $d t$ is given by $d z=e_{t} \sqrt{d t}$ where $e_{t}$ has zero mean and unit standard deviation $\left(e_{t}\right.$ is $N(0,1)$ and $E\left(e_{t} e_{s}\right)=0$, for $\left.t \neq s\right)$. Therefore, changes in $V$ over time are a function of a known proportion growth rate parameter $\mu$ and $\sigma$, which is governed by the increment of Weiner process, $d z^{[11]}$. It is modelled as the discounted as the discounted sum of random draws from the distribution of expected returns from investing $(R)$, annualized and projected into perpetuity. More specific, the opportunity to invest for time $t\left(V_{t}\right)$ is given by Equation 11 while for a period hence is $\left(V_{t+1}\right)$ is given by Equation $12^{[11,12]}$.

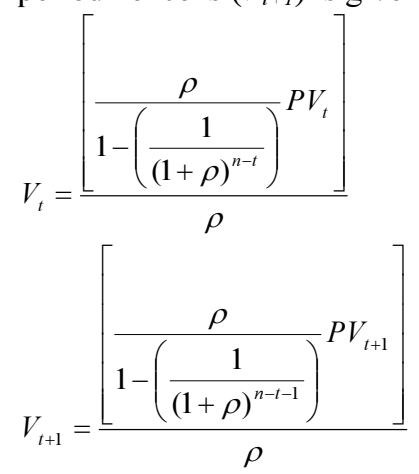

where, $P V_{t}=\sum_{i=0}^{n} \frac{R_{t+i}}{(1+\rho)^{i}}$ and

$P V_{t+1}=\sum_{i=1}^{n+1} \frac{R_{t+i}}{(1+\rho)^{i-1}}$ with $R$ the expected return 
from investing, $\rho$ a discount rate and $t$ the investment time period.

The trend $(\mu)$ of the geometric Brownian motion process is estimated by

$\mu_{V} \approx \frac{1}{N} \sum_{j=1}^{N}\left[\Delta \ln V_{j}\right]$

where, $E\left[\Delta \ln V_{j}\right] \Rightarrow 0$ and the varianve of the opportunity value to invest is estimated by

$\sigma_{V} \approx \frac{1}{N} \sum_{j=1}^{N}\left[\Delta \ln V_{j}-\mu_{V}\right]^{2}$

where, $E\left[\left(\ln V_{j}-\mu_{V}\right)^{2}\right]>0$

To calculate the statistics $\mu_{v}$ and $\sigma_{v}$ from simulation data, the mean of $N$ simulated log differences investing in $t$ and $t+1$ is calculated. The difference between natural logarithms of $V_{t}$ and $V_{t+1}$ gives a discrete estimate of the change in the value of investment opportunity occurring over an increment of a geometric Brownian motion process. An estimate of this discrete difference is simulated over 25,000 iterations. The evaluation of variance of the opportunity to invest is used to estimate the optimum investment trigger under uncertainty and irreversibility.

\section{RESULTS}

The enlargement project of the study area, called "pastureland of Siatista", is projected to take place in the Western Macedonia (north-western Greece) and involves mainly improvemnet investmentes of the pastureland; especially infrastructures, education and new cultivations. The "pastureland of Siatista" is a public project which is financing by the Greek Ministry of Agriculture. Therefore, a large part of the total cost will be recovered from the beneficiaries as pasture defrayment or indirect taxation.

The total annual amount of aboveground biomass production approaches the 4,107,207 kg. The expenses of the enlargement project play an important role in the investor's decision, as they constitute a significant part of the total cost. The economic profitability of the project is very important, notably in a world where funds available for agricultural investments are limited. In this work, a typical investment option is evaluated by applying DCF and a real options approach. The net annual returns include all the expected benefits of the project according to the literature. After the enlargement of the projects, the pasture storage are expected to increase by $30 \%$.

Both NPV and IRR have been applied for a period of fifteen years. NPV equals to $€ 408,530.00$ and IRR equals to $7.05 \%$, suggesting that this particular investment is economically feasible. The sensitivity analysis (after $\pm 20 \%$ fluctuation of each factor ceteris paribus) of the NPV shows that the enlargement project is, in any case, an acceptable investment.
Then, the real option approach is applied utilizing the same criteria as above. Monte Carlo simulation is used to designate the mean and the variance of net annual returns of the project which are determined by 25,000 Monte Carlo iterations through @RISK software $^{[23]}$. The two most important uncertainty sources, of the enlargement project, are the pasture capacity (natural source) and the unit price (economic source).

The pasture capacity has been modelled as a gamma distribution. The expected mean pasture capacity is $400,000 \mathrm{kgr}$ per year with a standard deviation equal to $48,000 \mathrm{kgr}$ per year. The selling price of the single pasture unit (kgr) has been modelled as triangular distribution. The most likely price, administered by the central municipality corporation, is $€ 0.10$ per kgr, with expected price ranging from $€ 0.05$ per kgr to $€ 0.18$ per kgr. In economic terms, the meaning of the price above is that in pasture scarcity years the selling price of each unit may be higher than in pasture plethora years. Simulated net annual returns $[E(R)]$ from investing in the specific project have an expected mean equal to $€ 145,000$ with a standart deviation of $€ 96,000$.

One hundred iterations (simulations) were used to derive the parameters $\mu_{v}$ and $\sigma_{v}$ on the value of the opportunity to invest in an enlargement project. The average investment cost of the project is estimated to $€ 7,658,000$ (including the cost of allocation canals). The annuity has been computed assuming a long-run loan of fifty years' duration and $6.5 \%$ rate of interest. The Marshallian trigger $(M)$ of the initial cost is equal to $€ 522,189.12$ (Table 1$)$. The net annual returns $(\beta / \beta-1)$ of the investment have to be 1.4864 times greater for the corresponding Marshallian trigger, which means that the net annual returns have to be larger than $€ 799,332.09$ (Fig. 1).

Table 1: Parameters for value of investment opportunity and value of waiting

\begin{tabular}{ll}
\hline Parameters & Values \\
\hline$\sigma^{2}$ & 0.0228 \\
$\beta / \beta-1$ & 1.4864 \\
$\mathrm{~B}$ & $2.672 \mathrm{E}-13$ \\
$\rho$ & $6.50 \%$ \\
$\rho$ & $9.16 \%$ \\
$\mathrm{M}$ & $522,189.12$ \\
$\mathrm{H}$ & $799,332.09$ \\
$\mathrm{H}-\mathrm{M}$ & $277,142.97$ \\
$\rho \mathrm{V}(\mathrm{R})$ & $277,142.97$ \\
\hline
\end{tabular}

Thus, while investing in the specific project proved economically feasible according to NPV criterion, it is not economically feasible according to a methodology incorporating real options approach. The simulated annual returns $[E(R)]$ have to be larger than $€ 799,332.09$ according to the optimal investment trigger $(H)$; otherwise they are equal to $€ 214,667.13$. The real options procedure revealed that the investment must be postponed and decision makers must keep the 


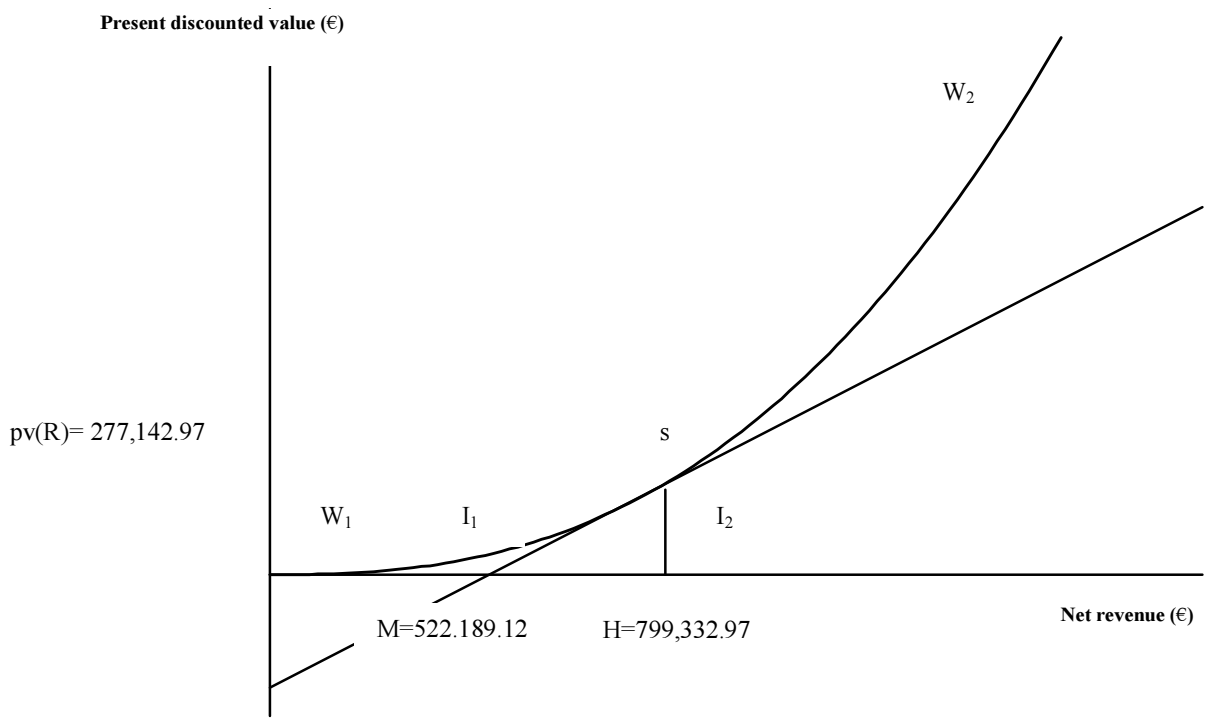

Fig. 1: Optimal investment policy

option of investing on hold. Thus, adopting a real options approach alters the results and enriches the assessment analysis.

As it can be seen from Table 1 the discount rate of return $(\rho)$ differs from the modified one $\left(\rho^{\prime}\right)$ which includes uncertainty and irreversibility. The modified minimum rate of return ( $\rho$ ') estimated at $9.16 \%$ has to be used hereafter for the optimal investment decision, instead of the traditional discount rate of return $(\rho)$.

The value of waiting can be illustrating using a diagram (Fig. 1) described by Dixit ${ }^{[18]}$. This involves a single project with irreversible expenditure $(I)$ that yields a stream of net revenue $(R)$ which lasts forever. This revenue stream is uncertain with a given probability distribution and is discounted by a positive interest rate $(r)$. The standard present discount approach implies that one should invest whenever $R / r$ exceeds $I$. This involves the implicit assumption that the choice is between investing now or never. However, the additional possibility of waiting can be better than the possibility of not investing at all or implementing the investment immediately.

The optimal waiting time and therefore the optimal trigger point, is determined where the marginal value of waiting is equal to the marginal value of investing. The former is equal to the slope of the value of investing schedule shown as $W_{1} W_{2}$ in Fig. 1, where net revenue $(R)$ is on the horizontal axis and the present discounted value of the entire investment project $(R / r-I)$ is on the vertical axis. When the current value of $R$ is very low, the present discounted value of future receipts is also very low and the $W_{1} W_{2}$ schedules goes to zero from above as $R$ goes to zero. Increasing current values of $R$ raises the present discounted value of the project, resulting in the convex curve $W_{1} W_{2}$.
The marginal value of investing is equal to $1 / r$ and is equal to the slope of the $I_{1} I_{2}$ schedule, which shows the value of net revenue $(R / r-I)$ as a function of $R$. The optimal value for the net revenue is given by the trigger point which is where the two schedules are tangent to each other at point $I_{2}$. This is known as the smooth pasting condition which equates the marginal value of waiting with the marginal value of investing $^{[18]}$.

\section{CONCLUSION}

This study offers an example of contractual agreement within a large infrastructure project that can be assessed using real options techniques. In addition, an attempt has been made to employ both the NPV criterion and the real options approach to pastureland enlargement project and finally to compare results. Monte Carlo simulation is used to value the options as it offers the flexibility to directly simulate the underlying uncertainty factors and to capture a great deal of the complexity in the contractual terms.

Empirical results revealed that, according to the NPV criterion, the enlargement plan of the project is economically feasible. However, assuming the presence of uncertainty, application of a real options approach demonstrates that the NPV may lead stakeholders to faulty decisions, as the investment plan is rejected. The results indicate that the options have a significant value and highlight the fact that ignoring options value process can lead to a significant error. This obviously demonstrates the importance of combining the NPV criterion in infrastructure investments with the real options approach. 


\section{REFERENCES}

1. Papachristou, T.G. and A.S. Nastis, 1993. Diets of goats grazing oak shrublands of varying cover in Northern Greece. J. Range Manage., 46: 220-226.

2. Papachristou, T.G. and A.S. Nastis, 1993. Nutritive value of diet selected by goats grazing on kermes oak shrublands with different shrub and herbage cover in Northern Greece. Small Ruminant Res., 12: 35-44.

3. Dumont, B., M. Meuret and M. Prudhon, 1995. Direct observation of biting for studying grazing behavior of goats and lamas on garrigue rangelands. Small Ruminant Res., 16: 27-35.

4. Espejo-Diaz, M., 1996. Evaluation and Improvement of Efficacy of Animal Production Systems using Natural Resources by Grazing Ruminants in Mediterranean Areas: In: Zervas, N.P., Hatziminaoglou, J. (Eds.), Optimal Exploitation of Marginal Mediterranean Areas by Extensive Ruminant Production Systems. Intl. Symp., EAAP Publication No 83, Thessaloniki, Greece, June 18-20, pp: 105-112.

5. McDowell, L.R., 1985. Free-choice Mineral Supplementation and Methods of Mineral Evaluation. In: Nutrition of Grazing Ruminants in Warm Climates, Academic Press, Inc. San Diego, pp: 383-407.

6. Pérez-Corona, M.E., B.R. Vázquez de Aldana, B. García -Criado and A. García -Ciudad, 1998. Variations in nutritional quality and biomass production of semiarid grasslands. J. Range Manage., 51: 570-576.

7. Ramirez, R.G., 1999. Feed resources and feeding techniques of small ruminants under extensive management conditions. Small Rumin. Res., 34: 215-230.

8. George, M., G. Nader, N. McDougald, M. Connor and B. Frost, 2001. Annual range forage production. Univ. Calif. Div. Agric. Nat. Res. Rangeland Management Series Pub 8022, pp: 13.

9. Ramirez, R.G., 1996. Feed values of browse. In: VI International Conference on Goats Editorial. International Publishers, Beijing, China, pp: 510517.

10. Morck, R., E. Schwartz and D. Stangeland, 1989. The valuation of forestry resources under stochastic prices and inventories. J. Financial and Quantitative Analysis, 24: 473-487.
11. Dixit, A. and R.S. Pindyck, 1994. Investment under uncertainty, Princeton University Press, Princeton, NJ. H.N.M.S., 2005. Hellenic National Meteorological Service, Athens, Greece.

12. Papanikolaou, K., I. Nikolakakis, A. Imamidou, V. Pappa and V. Ntotas, 2002. Botanical and chemical composition of grazable material in Florina Greece rangelands and its role in developing of organic stock breeding. Animal Sci. Rev., 27: 4849.

13. Gittinger, J.P., 1986. Economic Analysis of Agricultural Projects. International Bank for Reconstruction and Development, The John Hopkins University Press, Baltimore.

14. Brealey, A.R. and S.C. Myers, 1991. Principles of Corporate Finance. 4th Edn. McGraw-Hill, Inc.

15. Luehrman, T.A., 1998. Investment opportunities as real options: Getting started on the numbers, Harvard Business Review, Jul.-Aug., pp: 51-67.

16. Dixit, A. and R.S. Pindyck, 1995. The options approach to capital investment, Harvard Business Review, May-June, pp: 105-115.

17. Dixit, A., 1992. Investment and hysteresis. J. Economic Perspectives, 6: 107-132.

18. Pindyck, R.S., 1991. Irreversibility, uncertainty and investment. J. Economic Literature, 29: 1110-1148.

19. Black, F. and M. Scholes, 1973. The pricing of options and corporate liabilities. J. Political Econ., 3: 637-654.

20. Louberge, H., S. Villeneuve and M. Chesney, 2002. Long-term risk management of nuclear waste: a real options approach. J. Economic Dynamics and Control, 27: 157-180.

21. Kassarr, I. and P. Lasserre, 2004. Species preservation and biodiversity value: A real options approach. J. Environmental Economics and Management, 48: 857-879.

22. Purvis, A., W.G. Boggess, C.B. Moss and J. Holt, 1995. Technology adoption decisions under irreversibility and uncertainty: An ex ante approach. Am. J. Agril. Econ., pp: 541-551.

23. Palisade Corporation, 2000.@RISK-Risk Analysis and Simulation Add-In for Microsoft Excel: A Software Package. Version 4, Newfield, NY. 